\title{
Development of a practical synthesis of etravirine via a microwave-promoted amination
}

\author{
Da Feng, Fenju Wei, Zhao Wang, Dongwei Kang ${ }^{*}{ }^{\circledR}$, Peng Zhan ${ }^{*}$ and Xinyong Liu*
}

\begin{abstract}
Background: Etravirine (ETV) was approved as the second generation drug for use in individuals infected with HIV-1 in 2008 by the U.S. FDA with its unique antiviral activity, high specificity, and low toxicity. However, there are some shortcomings of the existing synthetic routes, such as the long reaction time and poor yield.

Results: This article describes our efforts to develop an efficient, practical, microwave-promoted synthetic method for one key intermediate of ETV, which is capable of being operated on a scale-up synthesis level. Through this optimized synthetic procedure, the amination reaction time decreased from $12 \mathrm{~h}$ to $15 \mathrm{~min}$ and the overall yield improved from 30.4 to $38.5 \%$.
\end{abstract}

Conclusion: Overall, we developed a practical synthesis of ETV via a microwave-promoted method, and the synthetic procedure could be amenable to scale-up, and production costs could be significantly lowered.

Keywords: Etravirine, Microwave-promoted, Amination, Synthesis

\section{Background}

HIV-1 non-nucleoside reverse transcriptase inhibitors (NNRTIs) represent a potent and promising antiviral agents that specifically target the HIV-1 reverse transcriptase (RT), the primary target for anti-HIV drugs. The NNRTIs were the major components of highly active antiretroviral therapy (HAART). However, the rapid emergence of drug-resistant HIV-1 strains limited their clinical use [1-4]. Etravirine, 2,4-[[6-amino5-bromo-2-[(4-cyanophenyl)amino]-4-pyrimidinyl] oxy]-3,5-dimethylbenzonitrile, a second-generation drug of the diarylpyrimidine-based NNRTIs, was approved in 2008 by the U.S. Federal Drug Administration (FDA) for use in HAART [5]. Etravirine is a well-tolerated NNRTI with higher genetic barrier for resistance and good safety profiles compared to the first-generation NNRTIs [6].

\footnotetext{
*Correspondence: kangdongwei@126.com; zhanpeng1982@163.com; xinyongllab@163.com

Department of Medicinal Chemistry, Key Laboratory of Chemical Biology (Ministry of Education), School of Pharmaceutical Sciences, Shandong University, 44 West Culture Road, Ji'nan 250012, Shandong, People's Republic of China
}

However, there are some shortcomings of the existing synthetic routes, such as the long reaction time and poor yield, which lead to the expensive price of etravirine. Therefore, an efficient synthesis of etravirine holds great potential in both scientifically and socially.<smiles>Cc1cc(C#N)cc(C)c1Oc1nc(Nc2ccc(C#N)cc2)nc(N)c1Br</smiles>

Etravirine (1)

\section{Medicinal chemistry synthesis of etravirine}

The synthetic routes of etravirine disclosed are outlined in Schemes 1, 2, 3 and 4, which is mainly divided into two methods: (1) Method 1: The halogenated pyridines ( 2 or

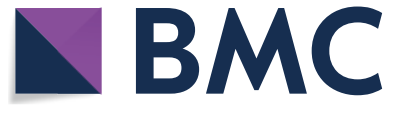

(c) The Author(s) 2018. This article is distributed under the terms of the Creative Commons Attribution 4.0 International License (http://creativecommons.org/licenses/by/4.0/), which permits unrestricted use, distribution, and reproduction in any medium, provided you give appropriate credit to the original author(s) and the source, provide a link to the Creative Commons license, and indicate if changes were made. The Creative Commons Public Domain Dedication waiver (http://creativecommons.org/ publicdomain/zero/1.0/) applies to the data made available in this article, unless otherwise stated. 
6) are used as starting materials (Schemes 1, 2) [6, 7]; (2) Method 2: 4-guanidinobenzonitrile (12) is selected as starting material or intermediate (Schemes 3,4$)[8,9]$.

In Scheme 1, the starting material 5-bromo-2,4,6trichloropyrimidine (2) was treated with 4-aminobenzonitrile (3) in refluxing dioxane to give the intermediate 4. Treatment of $\mathbf{4}$ with 4-hydroxy-3,5-dimethylbenzonitrile in $N$-methylpyrrolidone afforded the key intermediate 5. Then etravirine was obtained by the ammonification reaction of intermediate 5 with ammonia under the condition of high pressure and high temperature.

In another synthetic route (Scheme 2), the starting material 2,4,6-trichloropyrimidine (6) was treated with 4-hydroxy-3,5-dimethylbenzonitrile (7) under the weakly alkaline condition yield the intermediate $\mathbf{8}$. Then 8 reacted with 4-aminobenzonitrile (3) provided the intermediate 9 and by-product 10, which was separated from each other by recrystallization. Then etravirine was obtained by the ammonification and bromination of intermediate 9 successively. The yield of the overall route can up to $30.4 \%$.

In Scheme 3, etravirine was obtained with the 4-guanidinobenzonitrile (12) as starting material. Firstly, 12 was cyclized with diethylmalonate in the presence of sodium ethoxide in ethanol to give the intermediate 13, which was subsequently treated with $\mathrm{POCl}_{3}$ to form the corresponding derivative 14. Then the bromination of $\mathbf{1 4}$ afforded the intermediate 4, which passed through four successive reactions (nucleophilic substitution with the sodium salt of 7 , and ammonification) to give etravirine. In Scheme 4, the synthesis route very similar to that in Scheme 3 . The more commercially available 4-aminobenzonitrile (3) was used as starting material in this route. Besides, the sequence of the last three steps in Scheme 4 (nucleophilic substitution, ammonification and bromination) is distinct from those in Scheme 3.

Taken together, in the above synthesis methods of etravirine, problems like the following still exist: (1) The starting materials are difficult to obtain (exemplified by compound 2); (2) In the route employing 4-guanidinobenzonitrile as starting material or intermediate, the overall yield is low; (3) The longer amination reaction time and lower yield of the overall route when halogenated pyridine was used as starting material. Therefore, there have an urgent need to find more efficient and practicable methods in the pharmaceutical industry to synthesize etravirine and its intermediates. Comparative analysis the existing routes described above, the route in Scheme 2 has advantages of the accessibility of raw materials and the simplicity of synthetic steps. Inspired by the route in Scheme 2 and considering its deficiency, we became interested in designing a more efficient synthesis through optimizing the amination method with the aim to increase the overall yield of the route and shorten the longer amination reaction time.

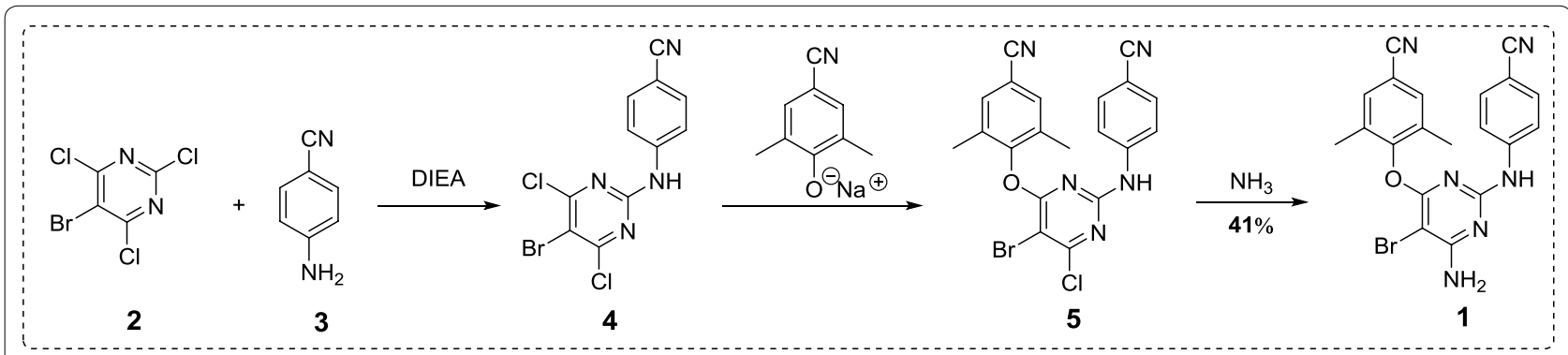

Scheme 1 Synthesis of etravirine with 5-bromo-2,4,6-trichloropyrimidine (2) as starting material [6]

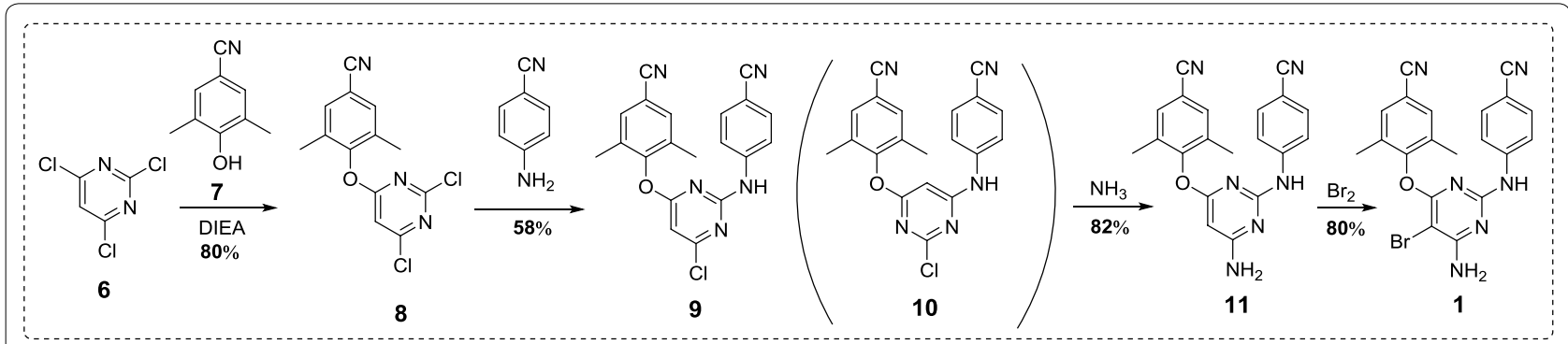

Scheme 2 Synthesis of etravirine with 2,4,6-trichloropyrimidine (6) as starting material [7] 


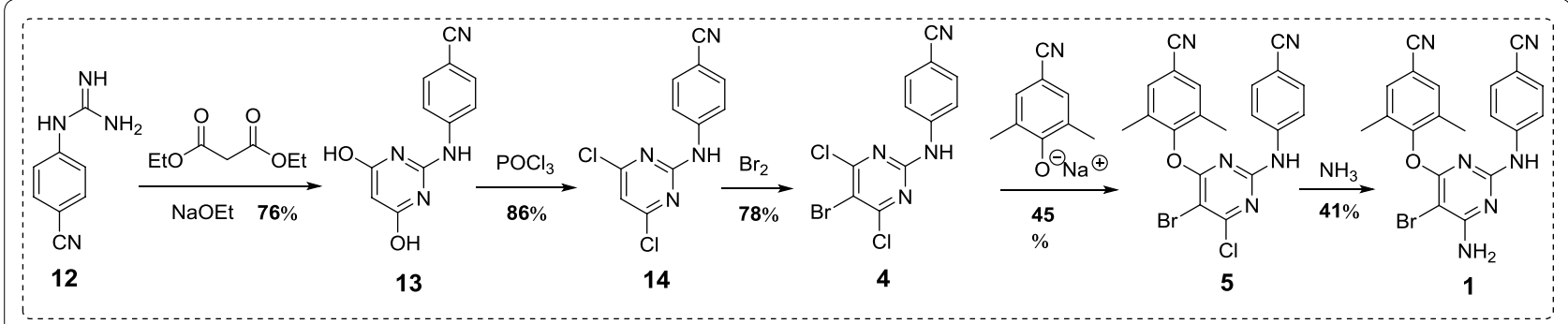

Scheme 3 Synthesis of etravirine with 4-guanidinobenzonitrile (12) as starting material [8]

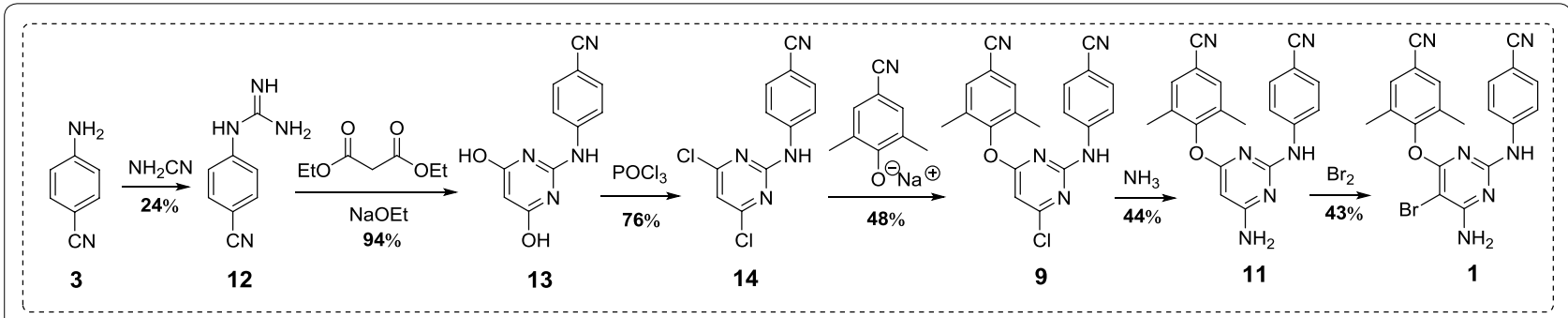

Scheme 4 Synthesis of etravirine with 4-aminobenzonitrile (3) as intermediate [9]

\section{Results and discussions}

Since Gedye and Giguere published their first articles about microwave-assisted syntheses in household microwave ovens in 1986 [10, 11], the microwave-assisted synthesis method have attracted an increasing number of chemists' attention for its high efficiency in chemical process. The method have been used in many fields successfully. Considering the longer amination time of the existing process route, we attempt to apply this efficient method in the amination reaction for the purpose of reducing reaction time and improving the yield.

In the preliminary study, we conducted the reaction in an autoclave as the conventional synthesis [5] (Scheme 5). The amination reaction performed very well as the literature reported and the yield ranged from 82.7 to $83.6 \%$. Then we attempted the reaction in the microreactor. When we conducted our first attempt, dioxane, acetonitrile and tetrahydrofuran was used as solvent. The results were frustrated and there no desired product was obtained. We speculated that the poor solubility of the intermediate 9 in these solvent lead to the failure of the reaction. Then some good dissolving solvent of $\mathbf{9}$ were chosen, such as dimethylformamide (DMF), dimethylsulfoxide (DMSO) and $N$-methylpyrrolidone (NMP). The results were depicted in Table 1 , the reaction conducted very well in all the three solvent with moderate to good yield compared to our preliminary attempt. The results demonstrated that the reaction have the best yield in $N$-methylpyrrolidone, so it was selected as solvent for the further optimization of the microwave reaction. Further
Table 1 Optimization of reaction conditions

\begin{tabular}{llllll}
\hline Solvent & Method $^{\mathbf{a}}$ & $\begin{array}{l}\text { Temperature } \\
\left({ }^{\circ} \mathrm{C}\right)\end{array}$ & Time & Pressure (psi) & Yield \% \\
\hline Dioxane & $\mathrm{A}$ & 120 & $12 \mathrm{~h}$ & - & 83.5 \\
$\mathrm{CH}_{3} \mathrm{CN}$ & $\mathrm{A}$ & 120 & $12 \mathrm{~h}$ & - & 82.7 \\
$\mathrm{NMP}$ & $\mathrm{A}$ & 120 & $12 \mathrm{~h}$ & - & 83.6 \\
Dioxane & $\mathrm{B}$ & 120 & $30 \mathrm{~min}$ & 130 & 0 \\
$\mathrm{CH}_{3} \mathrm{CN}$ & $\mathrm{B}$ & 120 & $30 \mathrm{~min}$ & 130 & 0 \\
$\mathrm{THF}$ & $\mathrm{B}$ & 120 & $30 \mathrm{~min}$ & 130 & 0 \\
DMF & $\mathrm{B}$ & 120 & $30 \mathrm{~min}$ & 128 & 67.7 \\
DMSO & $\mathrm{B}$ & 120 & $30 \mathrm{~min}$ & 127 & 72.1 \\
NMP & $\mathrm{B}$ & 120 & $30 \mathrm{~min}$ & 127 & 81.4 \\
\hline
\end{tabular}

a Method A: Conventional synthesis: $25 \%$ aq ammonia, autoclave, $120^{\circ} \mathrm{C}$, $12 \mathrm{~h}$; Method B: Microwave-assisted synthesis: $25 \%$ aq ammonia, 10-30 min, $120-150^{\circ} \mathrm{C}$

investigation of the amination reaction mainly focus on the amination temperature and reaction time (Table 2). We can conclude that the yield was improved with the increased reaction time and temperature. But there have decreasing tendency of the yield when the temperature above $130{ }^{\circ} \mathrm{C}$ and reaction time more than $15 \mathrm{~min}$. After an orthogonal experiment, the optimized conditions of the amination reaction was determined as follows: in the microwave reactor with $N$-methylpyrrolidone as solvent and reacted in $130{ }^{\circ} \mathrm{C}$ for $15 \mathrm{~min}$. The yield of amination reaction can up to $85.6 \%$, which was higher than that of the conventional synthesis method (83.6\%). 
Table 2 Optimization of amination reaction conditions

\begin{tabular}{|c|c|c|c|c|c|c|}
\hline \multirow[b]{2}{*}{ Tem. $/{ }^{\circ} \mathrm{C}:$} & \multicolumn{6}{|c|}{ Yield/\% } \\
\hline & 110 & 120 & 125 & 130 & 135 & 140 \\
\hline \multicolumn{7}{|l|}{ Time/min } \\
\hline 5 & 32.4 & 42.1 & 45.3 & 43.2 & 45.2 & 47.6 \\
\hline 10 & 46.7 & 64.5 & 74.2 & 71.2 & 76.3 & 73.6 \\
\hline 15 & 64.4 & 78.3 & 82.4 & 85.6 & 85.3 & 85.5 \\
\hline 20 & 74.3 & 80.8 & 82.6 & 85.3 & 85.6 & 85.1 \\
\hline 25 & 80.4 & 81.2 & 83.1 & 85.7 & 83.1 & 84.3 \\
\hline 30 & 82.5 & 81.4 & 82.1 & 84.2 & 84.2 & 84.1 \\
\hline
\end{tabular}

\section{Discussion}

The first step of the process route is a typical $\mathrm{S}_{\mathrm{N}} \mathrm{Ar}$ (addition-elimination) process (Scheme 6). Treatment of equimolar amounts of 4-hydroxy-3,5-dimethylbenzonitrile (7) with 2,4,6-trichloropyrimidine (6) in the presence of potassium carbonate may be afford two mono-substituted products $\mathbf{8}$ and $\mathbf{1 7}$ at the position of $\mathrm{C}_{4}-\mathrm{Cl}$ and $\mathrm{C}_{2}-\mathrm{Cl}$ of the staring material 6 . But the monosubstituted product $\mathbf{8}$ were obtained with excellent yields, for the reason that there exist a selectivity between $\mathrm{C}_{4}-\mathrm{Cl}$ and $\mathrm{C}_{2}-\mathrm{Cl}$ of compound 6 [12]. On account of the $\mathrm{S}_{\mathrm{N}} \mathrm{Ar}$ (addition-elimination) process is thermodynamical control, so the product depend on the stabilization of the intermediate Meisenheimer complex. Compared to the Meisenheimer intermediate $\mathbf{1 6}$ where the ring<smiles>Cc1cc(C#N)cc(C)c1Oc1cc(Cl)nc(Nc2ccc(C#N)cc2)n1</smiles>

nitrogen ortho to the tetrahedral carbon, the intermediate $\mathbf{1 5}$ with the para-quinoid structure can be better bear the negative charge and more stabilization [12], which gives reasonable account for the single mono-substituted products 8 .

\section{Conclusions}

Etravirine is an essential medicine for the treatment of HIV, which is still inaccessible to millions of people worldwide. To overcome the disadvantageous issues in the existing synthetic methods of etravirine, an efficient and practical synthetic method was optimized in this article. The synthesis was achieved using a linear approach starting from 2,4,6-trichloropyrimidine through a sequence of nucleophilic substitution, ammonification and bromination (Scheme 7). The microwavepromoted amination is the most critical step of this route, and it shorten the amination reaction time from $12 \mathrm{~h}$ to $15 \mathrm{~min}$. Moreover, the overall yield of the synthetic route is improved from 30.4 to $38.5 \%$ over 4 linear steps. To the best of our knowledge, this is the highest yield for etravirine that has been reported. Moreover, all the synthetic process does not require purification by column chromatography, and the formation of impurities could be suppressed very well. Accordingly, the synthetic procedure could be amenable to scale-up, and production costs could be significantly lowered through this microwavepromoted method.

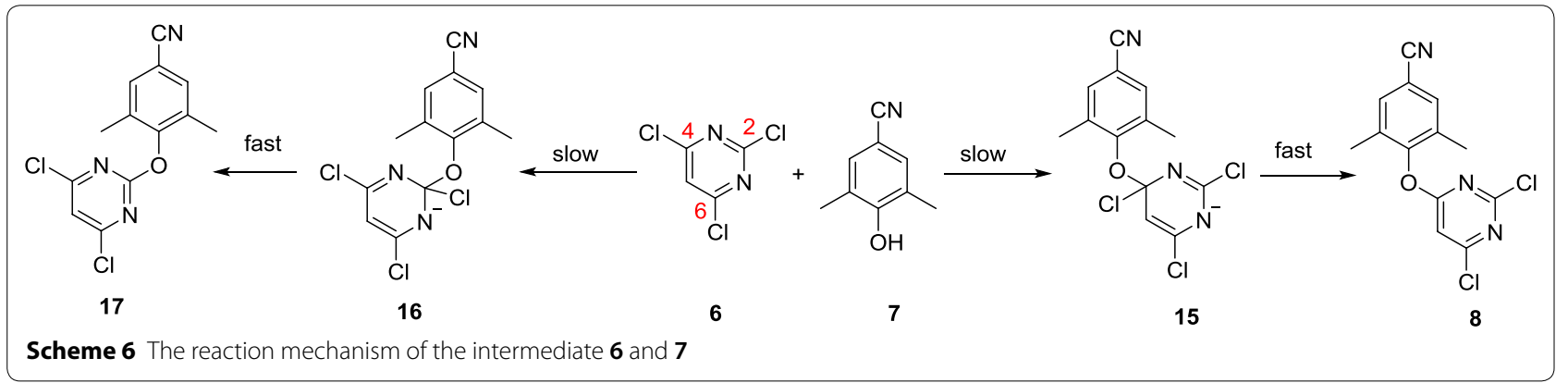




\section{Experimental section}

All melting points were determined on a micro melting point apparatus and are uncorrected. ${ }^{1} \mathrm{H}$-NMR spectra were obtained on a Bruker Avance 400 NMR spectrometer in the indicated solvents. Chemical shifts are expressed in $\delta$ units and TMS as internal reference. Mass spectra was taken on a LC Autos ampler Device: Standard G1313A instrument. TLC was performed on Silica Gel GF254 for TLC (Merck) and spot was visualized by iodine vapours or irradiation with UV light $(\lambda=254 \mathrm{~nm})$. The microwave reaction was conducted on a CEM Discover $(0-600 \mathrm{~W}, 2450 \mathrm{MHz})$ instrument and the conventional high pressure reaction was performed on Parr 4590 instrument. Concentration of the reaction solutions involved the use of rotary evaporator at reduced pressure.

\section{4-[(2,6-Dichloro)-4-pyrimidinyloxy]-3,5-dimethylbenzoni- trile (8)}

2,4,6-Trichloropyrimidine 6 (110 mmol, $20.0 \mathrm{~g}$ ), diisopropylethylamine (132 mmol, $17.0 \mathrm{~g}$ ) and 3,5-dimethyl-4-hydroxybenzonitrile 7 (110 mmol, $16.2 \mathrm{~g}$ ) were dissolved in 1,4-dioxane $(100 \mathrm{~mL})$ and the mixed solution was heated at $70{ }^{\circ} \mathrm{C}$ for $2 \mathrm{~h}$. After the reaction mixture was brought to $10-15{ }^{\circ} \mathrm{C}, 200 \mathrm{~mL}$ water was poured into the mixture and stirred for another $30 \mathrm{~min}$, filtrated. Then the wet cake was dried at $55-60{ }^{\circ} \mathrm{C}$ under vacuum to give the intermediate 8 as white solid with a yield of $92.5 \% .{ }^{1} \mathrm{H}$ NMR (400 MHz, DMSO- $\left.d_{6}, \mathrm{ppm}\right) \delta: 7.76\left(2 \mathrm{H}, \mathrm{s}, \mathrm{C}_{3}, \mathrm{C}_{5}-\right.$ $\mathrm{Ph}-\mathrm{H}), 7.64(1 \mathrm{H}, \mathrm{s}$, pyrimidine- $\mathrm{H}), 2.12\left(6 \mathrm{H}, \mathrm{s}, \mathrm{CH}_{3}\right)$. ESI-MS: $\mathrm{m} / \mathrm{z}$ 294.28(M+1). $\mathrm{C}_{13} \mathrm{H}_{9} \mathrm{Cl}_{2} \mathrm{~N}_{3} \mathrm{O}$ (293.01), mp: $207-209^{\circ} \mathrm{C}$.

\section{4-[[6-Chloro-2-[(4-cyanophenyl)amino]-4-pyrimidinyl]} oxy]-3,5-dimethylbenzonitril (9)

Compound 8 (68 mmol, $20.0 \mathrm{~g}$ ) and 4-aminobenzonitrile (68 mmol, $8.0 \mathrm{~g}$ ) were dissolved in $\mathrm{N}$-methylpyrrolidone $(100 \mathrm{~mL})$ at $0-5{ }^{\circ} \mathrm{C}$, then the solution was added potassium tert-butoxide (136 mmol, $15.3 \mathrm{~g}$ ) over a period of $30 \mathrm{~min}$ and stirred for another $2 \mathrm{~h}$ at $0-5{ }^{\circ} \mathrm{C}$. Then the mixture was added to $500 \mathrm{~mL}$ water slowly and the resulting precipitate was filtered. The obtained residue was suspended in water $(200 \mathrm{~mL})$ and acidified to $\mathrm{pH}$ 6-7 with $3 \mathrm{M}$ hydrochloric acid solution, filtered and dried at $55-60{ }^{\circ} \mathrm{C}$ under vacuum to give the crude product, which was purified by ethyl acetate treatments $(2 \times 200 \mathrm{~mL})$ at $70{ }^{\circ} \mathrm{C}$ for $30 \mathrm{~min}$ followed by filtration at $10^{\circ} \mathrm{C}$ and washing the cake with $20 \mathrm{~mL}$ of chilled ethyl acetate. Then the wet cake was finally dried at $50{ }^{\circ} \mathrm{C}$ under vacuum to give the intermediate 9 as white solid with a yield of $60.6 \% .{ }^{1} \mathrm{H}$ NMR $\left(400 \mathrm{MHz}, \mathrm{DMSO}-d_{6}, \mathrm{ppm}\right) \delta: 10.56(1 \mathrm{H}, \mathrm{s}, \mathrm{NH})$, $7.79\left(2 \mathrm{H}, \mathrm{s}, \mathrm{C}_{3}, \mathrm{C}_{5}-\mathrm{Ph}^{\prime}-\mathrm{H}\right), 7.45-7.51(4 \mathrm{H}, \mathrm{m}, \mathrm{Ph}-\mathrm{H})$, $6.93(1 \mathrm{H}, \mathrm{s}$, pyrimidine- $\mathrm{H}), 2.13\left(6 \mathrm{H}, \mathrm{s}, \mathrm{CH}_{3}\right)$. ESIMS: $\mathrm{m} / \mathrm{z}: 376.5(\mathrm{M}+1), 393.3(\mathrm{M}+18), 398.4(\mathrm{M}+23)$. $\mathrm{C}_{20} \mathrm{H}_{14} \mathrm{ClN}_{5} \mathrm{O}$ (375.09), mp: $277-279^{\circ} \mathrm{C}$.

\section{4-[[6-Amino-2-[(4-cyanophenyl)amino]-4-pyrimidinyl] oxy]-3,5-dimethylbenzonitrile (11)}

A mixture of 9 (5.3 mmol, $2.0 \mathrm{~g}$ ), 25\% aq ammonia $(15 \mathrm{~mL})$, and $N$-methylpyrrolidone $(20 \mathrm{~mL})$ was put into a microwave reactor and set the condition for $130{ }^{\circ} \mathrm{C}$, $15 \mathrm{~min}$. In the reaction process, the pressure can up to $135 \mathrm{psi}$. After the reaction mixture was brought to $5-10{ }^{\circ} \mathrm{C}, 100 \mathrm{~mL}$ water was added to this solution followed stirring another $30 \mathrm{~min}$. The generated solid was filtered, washed with $100 \mathrm{~mL}$ of water and dried at $45-50{ }^{\circ} \mathrm{C}$ to give the crude intermediate $\mathbf{1 1}$ as white solid with a yield of $85.6 \% .{ }^{1} \mathrm{H}$ NMR $\left(400 \mathrm{MHz}\right.$, DMSO- $d_{6}$, ppm) $\delta: 9.57(1 \mathrm{H}, \mathrm{s}, \mathrm{NH}), 7.73\left(2 \mathrm{H}, \mathrm{s}, \mathrm{C}_{3}, \mathrm{C}_{5}-\mathrm{Ph}^{\prime}-\mathrm{H}\right), 7.65$ $\left(2 \mathrm{H}, \mathrm{d}, J=8.0 \mathrm{~Hz}, \mathrm{C}_{3}, \mathrm{C}_{5}-\mathrm{Ph}-\mathrm{H}\right), 7.46(2 \mathrm{H}, \mathrm{d}, J=8.0 \mathrm{~Hz}$, $\left.\mathrm{C}_{2}, \mathrm{C}_{6}-\mathrm{Ph}-\mathrm{H}\right), 6.80\left(2 \mathrm{H}, \mathrm{s}, \mathrm{NH}_{2}\right), 5.47(1 \mathrm{H}, \mathrm{s}$, pyrimidine$\mathrm{H}), 2.12\left(6 \mathrm{H}, \mathrm{s}, \mathrm{CH}_{3}\right)$. ESI-MS: $\mathrm{m} / \mathrm{z} 357.4(\mathrm{M}+1), 379.5$ $(\mathrm{M}+23) . \mathrm{C}_{20} \mathrm{H}_{16} \mathrm{~N}_{6} \mathrm{O}(356.14), \mathrm{mp}: 283-286^{\circ} \mathrm{C}$.

\section{Etravirine (1)}

To a cooled solution of $\mathbf{1 1}(8.4 \mathrm{mmol}, 3.0 \mathrm{~g})$ in DCM $(30 \mathrm{~mL})$ at $0-5^{\circ} \mathrm{C}$ was added bromine solution $(9.4 \mathrm{mmol}$, $1.5 \mathrm{~g}$ in $8 \mathrm{~mL}$ of DCM). The reaction was stirred at this temperature for $5 \mathrm{~h}$. Then the mixed solution was diluted

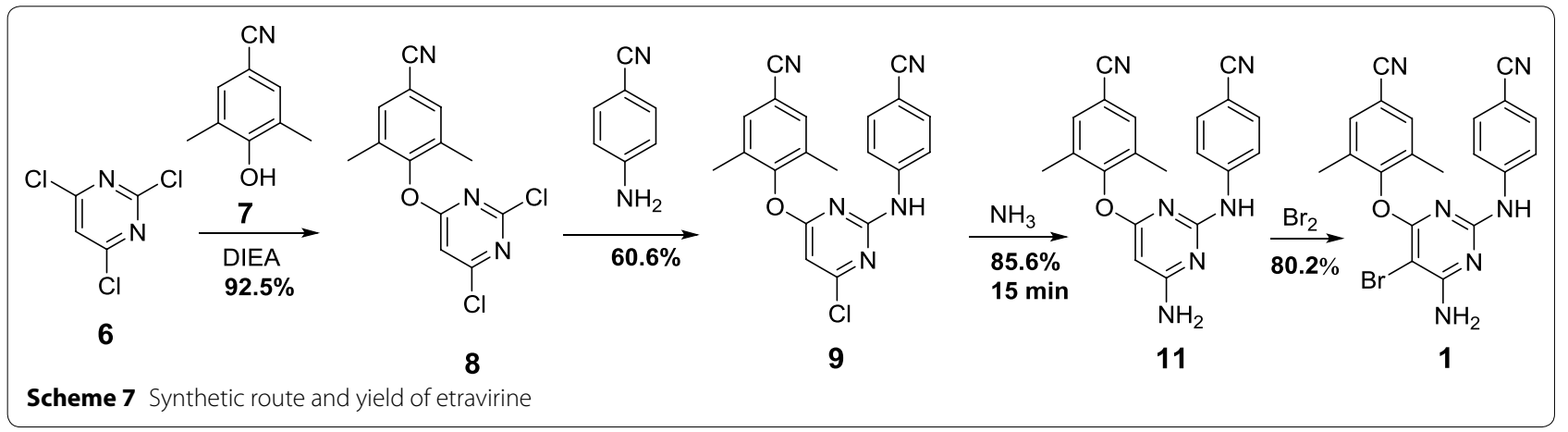


with water $(50 \mathrm{~mL})$ and basified with $4 \mathrm{M} \mathrm{NaOH}$ solution at $\mathrm{pH} 9-10$. The $\mathrm{pH}$ of the reaction was maintained between 8 and 9 over a period of another $1 \mathrm{~h}$ by adding $4 \mathrm{M} \mathrm{NaOH}$ solution and sodium metabisulphite solution. Then the obtained solid was filtered, washed with water $(30 \mathrm{~mL})$, and dried at $55-60{ }^{\circ} \mathrm{C}$ temperature under vacuum to get crude product, which was following dissolved in methanol $(40 \mathrm{~mL})$ at $55-60{ }^{\circ} \mathrm{C}$ and treated with activated charcoal. After charcoal clarification, methanol was distilled out, and the residue was recrystallized in ethyl acetate. The crystal was filtered and dried at $55-60{ }^{\circ} \mathrm{C}$ under vacuum to give etravirine with a yield of $80.2 \% .{ }^{1} \mathrm{H}$ NMR $\left(400 \mathrm{MHz}, \mathrm{DMSO}-d_{6}, \mathrm{ppm}\right) \delta: 9.60(1 \mathrm{H}, \mathrm{s}, \mathrm{NH})$, $7.75\left(2 \mathrm{H}, \mathrm{s}, \mathrm{C}_{3}, \mathrm{C}_{5}-\mathrm{Ph}^{\prime}-\mathrm{H}\right), 7.54\left(2 \mathrm{H}, \mathrm{d}, J=8.0 \mathrm{~Hz}, \mathrm{C}_{3}, \mathrm{C}_{5}-\right.$ $\mathrm{Ph}-\mathrm{H}), 7.43\left(2 \mathrm{H}, \mathrm{d}, J=8.0 \mathrm{~Hz}, \mathrm{C}_{2}, \mathrm{C}_{6}-\mathrm{Ph}-\mathrm{H}\right), 7.13(2 \mathrm{H}$, s, $\left.\mathrm{NH}_{2}\right), 2.12\left(6 \mathrm{H}, \mathrm{s}, \mathrm{CH}_{3}\right)$. ESI-MS: $\mathrm{m} / \mathrm{z}$ : $435.4(\mathrm{M}+1)$, 427.4 (M+3), 457.4 (M+23). $\mathrm{C}_{20} \mathrm{H}_{15} \mathrm{BrN}_{6} \mathrm{O}$ (434.05), mp: $254-256^{\circ} \mathrm{C}$.

\section{Authors' contributions}

DF, Conceived project, Design of experiments, Data acquisition and analysis, Writing —original draft, Writing — review and editing; FW, Compounds synthesis; ZW, Structure confirmation; DK, Conceived project, Data acquisition and analysis, Writing — review and editing; PZ, Supervision of experiments, Supervision, Writing — review and editing; XL, Conceived project, Supervision, Funding acquisition, Writing - review and editing. All authors read and approved the final manuscript.

\section{Acknowledgements}

We gratefully acknowledge financial support from the National Natural Science Foundation of China (NSFC Nos. 81420108027, 81573347), Young Scholars Program of Shandong University (YSPSDU No. 2016WLJH32), the Fundamental Research Funds of Shandong University (No. 2017JC006), and Key research and development project of Shandong Province (No. 2017CXGC1401).

\section{Competing interests}

The authors declare that they have no competing interests.

\section{Availability of data and materials}

All data are fully available without restriction.

\section{Consent for publication}

The authors declare that the copyright belongs to the journal.

\section{Ethics approval and consent to participate}

Not applicable.

\section{Publisher's Note}

Springer Nature remains neutral with regard to jurisdictional claims in published maps and institutional affiliations.

Received: 6 October 2018 Accepted: 27 November 2018

Published online: 20 December 2018

\section{References}

1. Zhan P, Chen X, Li D, Fang Z, De Clercq E, Liu X (2013) HIV-1 NNRTIs: structural diversity, pharmacophore similarity, and implications for drug design. Med Res Rev 33(Suppl 1):E1-E72

2. Zhan P, Pannecouque C, De Clercq E, Liu X (2016) Anti-HIV drug discovery and development: current innovations and future trends. J Med Chem 59:2849-2878

3. Shattock RJ, Warren M, McCormack S, Hankins CAAIDS (2011) Turning the tide against HIV. Science 333:42-43

4. Zuo X, Huo Z, Kang D, Wu G, Zhou Z, Liu X, Zhan P (2018) Current insights into anti-HIV drug discovery and development: a review of recent patent literature (2014-2017). Expert Opin Ther Pat 28:299-316

5. Kang D, Fang Z, Huang B, Lu X, Zhang H, Xu H, Huo Z, Zhou Z, Yu Z, Meng $\mathrm{Q}$, Wu G, Ding X, Tian Y, Daelemans D, De Clerca E, Pannecouque C, Zhan P, Liu X (2017) Structure-based optimization of thiophene[3,2-d]pyrimidine derivatives as potent HIV-1 non-nucleoside reverse transcriptase inhibitors with improved potency against resistance-associated variants. J Med Chem 60:4424-4443

6. De Corte B, De Jonge MR, Heeres J, Ho CY, Janssen PA, Kavash RW, Koymans LM, Kukla MJ, Ludovici DW, Van Aken KJ, Andries KJ. Preparation of arylaminopyrimidines as inhibitors of HIV replication. WO 2000027825

7. Shashikant J, Golak CM, Shyam T, Ashok C, Mukund KG (2010) An improved synthesis of etravirine. Org Process Res Dev 14:657-660

8. Ludovici DW, De Corte BL, Kukla MJ, Ye H, Ho CY, Lichtenstein MA, Kavash RW, Andries K, de Béthune MP, Azijn H, Pauwels R, Lewi PJ, Heeres J, Koymans LM, de Jonge MR, Van Aken KJ, Daeyaert FF, Das K, Arnold E, Janssen PA (2011) Evolution of anti-HIV drug candidates. Part 3: diarylpyrimidine (DAPY) analogues. Bioorg Med Chem Lett. 11:2235-2239

9. Reddy BP, Reddy KR, Reddy DM, Reddy RR, Krishna BV, Reddy AV. Preparation of an etravirine intermediate and polymorphs of etravirine. WO 2012001695

10. Richard G, Frank S, Kenneth W, Humera A, Lorraine B, Lena L, John R (1986) The use of microwave ovens for rapid organic synthesis. Tetrahedron Lett 27:279-282

11. Raymond JG, Terry LB, Scott MD (1986) Application of commercial microwave ovens to organic synthesis. Tetrahedron Lett 27:4945-4948

12. Thoms JD, Nagarajan A (1998) 2,4,6-Trichloropyrimidine. Reaction with 4-substituted phenolate ions. J Heterocyclic Chem. 35:269-273
Ready to submit your research? Choose BMC and benefit from:

- fast, convenient online submission

- thorough peer review by experienced researchers in your field

- rapid publication on acceptance

- support for research data, including large and complex data types

- gold Open Access which fosters wider collaboration and increased citations

- maximum visibility for your research: over 100M website views per year

At BMC, research is always in progress.

Learn more biomedcentral.com/submissions 